\title{
Engine Torque Ripple Cancellation With an Integrated Starter Alternator in a Hybrid Electric Vehicle: Implementation and Control
}

\author{
Roy I. Davis, Member, IEEE, and Robert D. Lorenz, Fellow, IEEE
}

\begin{abstract}
Integrated starter alternators (SAs) provide greater electrical generation capacity and the fuel economy and emissions benefits of hybrid electric automotive propulsion. The drive usually comprises a field-oriented induction motor or vector-controlled permanent-magnet motor coupled to the crankshaft of the engine directly or by a belt. These drives have high-bandwidth torque control and may be used for active cancellation of the significant ripple torque inherent in internal combustion engines. This paper presents an analytical model useful for the analysis of the combustion engine torque and describes a control system that uses observer-based high-fidelity torque feedforward and engine speed feedback to generate a disturbance input decoupling torque command for the SA to cancel the engine torque ripple.
\end{abstract}

Index Terms-Active flywheel, engine model, engine torque, hybrid vehicle, integrated starter alternator $(\mathrm{SA})$, observer, torque cancellation.

\section{INTRODUCTION}

$\mathbf{I}$ NTEGRATED starter alternators (SAs) provide greater electrical generation capacity and improve the fuel economy and emissions of hybrid electric vehicles [1]. The integrated SA is coupled to the combustion engine either directly or by a belt. In addition to enabling the fuel economy and emissions improvements, the availability of the SA to perform other functions provides further benefit to the vehicle. One such function is active crankshaft torque-ripple cancellation, in which the SA machine is controlled as a torque actuator to reduce or eliminate the "ac" content of the torque produced by the impulsive cylinder pressures in the engine [2], [3]. This is sometimes referred to as "active flywheel," although it does much more than a flywheel could do.

This paper presents a "disturbance input decoupling" control method using a highly accurate observer that combines feedforward and feedback signals to synthesize the torque control signal for the SA effectively to cancel the ripple torque of the engine. The paper also describes a novel internal combustion engine (ICE) model, the ac torque observer used to create the

Paper IPCSD 03-066, presented at the 2002 Industry Applications Society Annual Meeting, Pittsburgh, PA, October 13-18, and approved for publication in the IEEE TRANSACTIONS ON INDUSTRY APPLICATIONS by the Industrial Drives Committee of the IEEE Industry Applications Society. Manuscript submitted for review July 1, 2002 and released for publication July 22. 2003.

R. I. Davis is with Ballard Power Systems, Dearborn, MI 48121 USA (e-mail: roy.davis@ballard.com).

R. D. Lorenz is with the Departments of Mechanical Engineering and Electrical and Computer Engineering, University of Wisconsin, Madison, WI 53706 USA (e-mail: lorenz@engr.wisc.edu).

Digital Object Identifier 10.1109/TIA.2003.818972
SA control signal, and test results that illustrate the system performance.

\section{ICE MODEL}

An indirect injection four-cylinder diesel engine was used for this research. Fig. 1 shows an overall diagram of the engine, clutch, and vehicle model, assuming the four cylinder pressures $P_{1}(\theta)-P_{4}(\theta)$ and the starter alternator torque $M_{\mathrm{SA}}$ as inputs, with the engine and vehicle motion states as outputs. Since the rotor of the starter alternator is rigidly mounted to the crankshaft flange, the combustion torque $M_{\mathrm{ICE}}$ and $M_{\mathrm{SA}}$ additively produce the total shaft torque $M_{\mathrm{SHAFT}}$, and the SA motion states $(\theta$ and $\omega)$ are the same as the engine motion states. The clutch torque $M_{\mathrm{CLUTCH}}$ provides the external load to the shaft, including the vehicle load as transmitted through the spring and damper elements that act upon the relative angular displacement and velocity across the clutch. Friction also loads the shaft, as does the inertia of the SA rotor and the shaft itself. The combined inertia effects consist of a constant value and a crankangle-dependent value (more detail on the inertia effects is given below). The vehicle is simply represented by its equivalent inertia $J_{V}$ and standard road load forces (aerodynamic, grade, rolling resistance, and brake drag) reflected to the clutch output by means of a gear ratio (not shown). The system illustrated in Fig. 1, combined with a model of the SA and control system, was used to create the simulation results provided in this paper.

While shown in Fig. 1 simply as "kinematics" and four cylinder pressures, the workings of an internal combustion engine are very complex, from the gas dynamics of the cylinder charge to the complex physics of combustion. One objective of this work was to create a novel simplified engine model with a computationally efficient method for generating the combustion pressure pulses for each of the four cylinder pressures. A simplified representation of the piston and crankshaft kinematics converts the pressure pulses to indicated torque, and a time-varying (or crankangle-varying) inertia expression is used to represent the translating pistons as effective rotational inertias. Such a simple model was needed to minimize the computational resources needed to implement a real-time observer based on the model.

The nonlinear geometry of the engine's piston and crank mechanism, also known as a slider crank, is shown in Fig. 2. This represents one piston-cylinder combination, where $\theta$ is the angle of rotation of the crank about its centerline, $r$ is the 


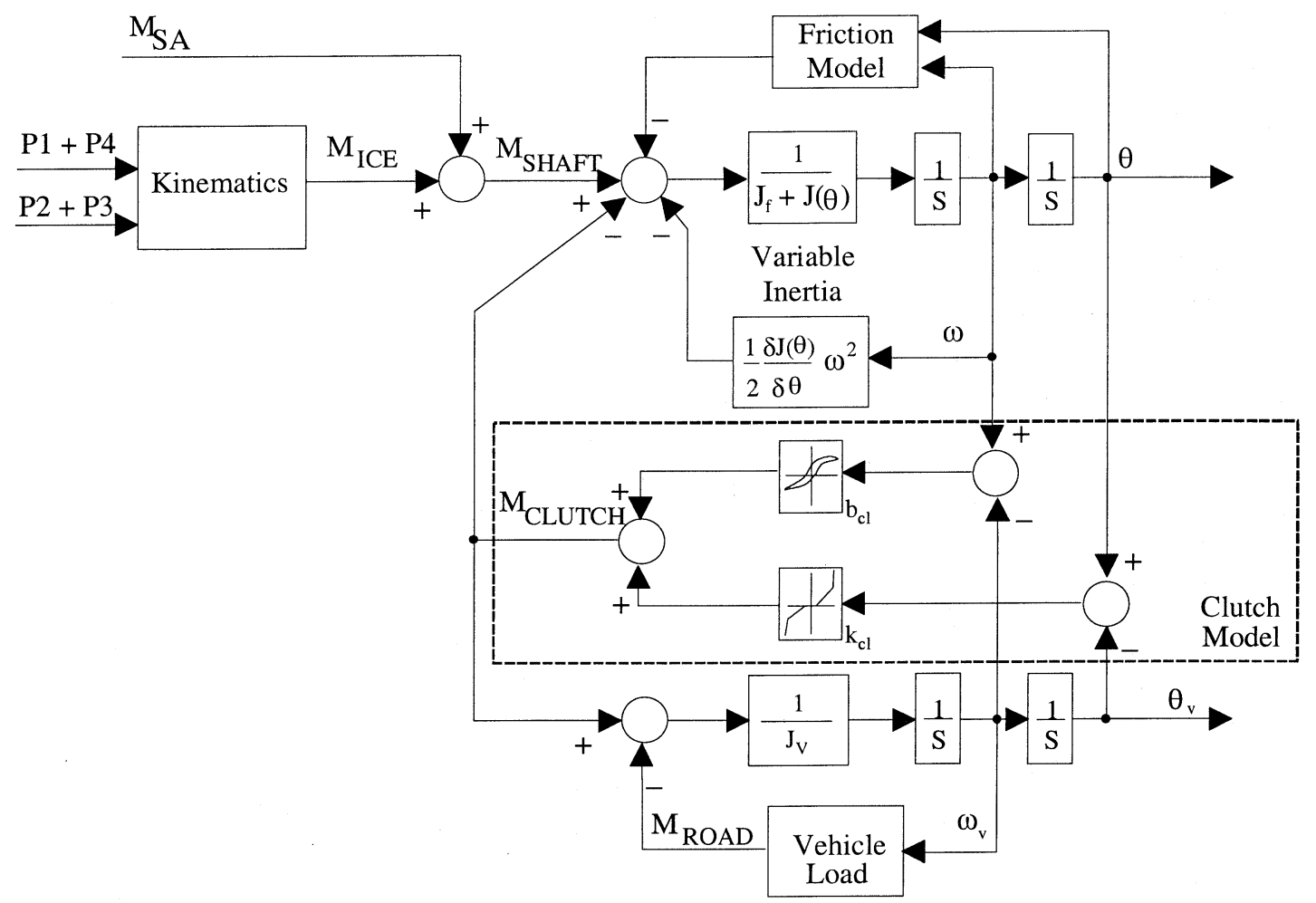

Fig. 1. Combined engine, clutch damper, and vehicle model.

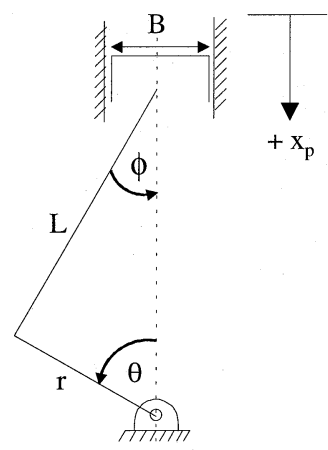

Fig. 2. Geometry of slider crank mechanism.

radius of the crank, $L$ is the length of the connecting rod, $x_{p}$ is the linear displacement of the piston, and $B$ is the cylinder bore diameter. To begin with, the indicated torque, $M_{\mathrm{ICE}}$, as a function of crankangle can be expressed as

$M_{\mathrm{ICE}}(\theta)=k_{1}\left[k_{2}\left(1.0+\frac{r}{L} \cos (\theta)\right)-k_{3}\left(1.0-\frac{r}{L} \cos (\theta)\right)\right]$

where

$$
\begin{aligned}
& k_{1}=\frac{\pi B^{2} r \sin (\theta)}{4} \\
& k_{2}=P_{1}(\theta)+P_{3}(\theta) \\
& k_{3}=P_{2}(\theta)+P_{4}(\theta) .
\end{aligned}
$$

It is important to include the crankangle-varying engine inertia $J(\theta)$ to properly model the dynamics of the crankshaft torque. The slider crank geometry gives rise to two effects: an inertia value which is a function of the angle $\theta$ and a LaGrangian term proportional to the partial derivative of the inertia and the square of crankshaft speed [4]. These expressions are given in (2) and (3), and are shown schematically in the block diagram of Fig. 1. Depending on its relative contribution, a friction torque term as shown in Fig. 1 can also be included if desired

$$
\begin{aligned}
J(\theta)= & 2 m_{\mathrm{rec}} r^{2}+\frac{m_{\mathrm{rec}} r^{4}}{2 L^{2}}-2 m_{\mathrm{rec}} r^{2} \cos (2 \theta) \\
& -\frac{m_{\mathrm{rec}} r^{4}}{2 L^{2}} \cos (4 \theta) \\
\frac{\partial J(\theta)}{\partial \theta}= & 4 m_{\mathrm{rec}} r^{2} \sin (2 \theta)+\frac{2 m_{\mathrm{rec}} r^{4}}{L^{2}} \sin (4 \theta)
\end{aligned}
$$

where $m_{\text {rec }}$ is the total reciprocating mass of the piston and connecting rod.

With an eye toward real-time implementation of this model as an observer, as mentioned above, a simple but accurate method is required to compute the impulsive cylinder pressures. The torque ripple that is generated by the pressure pulses is considered here as a disturbance input. Thus, it is important to represent the pressures as accurately as possible without relying on complicated derivations of gas dynamics and chemical thermodynamics [5]-[8].

The combustion pressure waveform can be accurately modeled by considering the underlying mechanisms at work in the cylinder. That is, to obtain instantaneous cylinder pressure we can add a motoring pressure due simply to the change in cylinder volume as the crank rotates (without combustion) to an incremental pressure produced by combustion of the fuel. The 


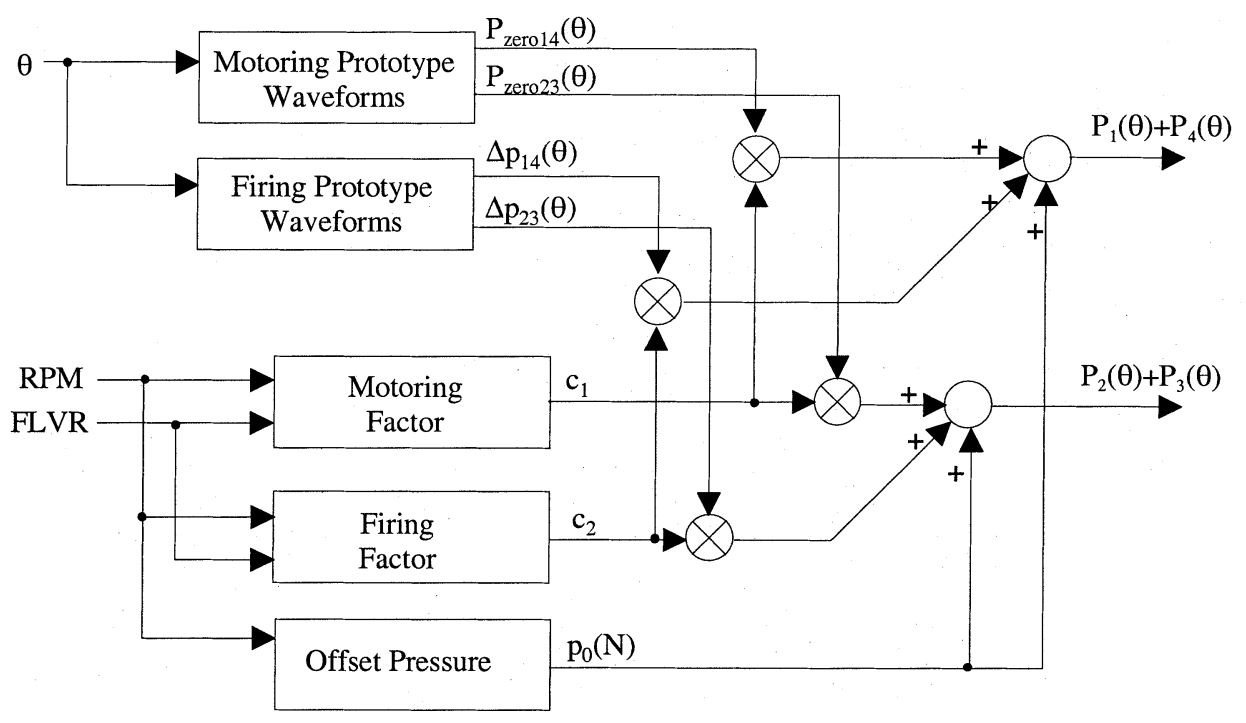

Fig. 3. Simulation block diagram for final cylinder pressure model.

cylinder volume as a function of crankangle and the resulting motoring pressure can be computed from

$$
\begin{aligned}
& V(\theta)=V_{c}+\frac{\pi B^{2}}{4}\left(r+L-r \bullet \cos (\theta)-\sqrt{L^{2}-r^{2} \bullet \sin ^{2}(\theta)}\right) \\
& P(\theta)=\frac{P(0)}{\left(\frac{V(\theta)}{\left(V_{d}+V_{c}\right)}\right)^{n}}
\end{aligned}
$$

where $V(\theta)$ is the cylinder dynamic volume, $V_{c}$ is the cylinder clearance volume, $V_{d}$ is the cylinder displaced volume, $P(\theta)$ is the motoring pressure, $P(0)$ is the average value of the intake manifold pressure, and $n$ is the exponent representing the isotropic expansion.

The motoring pressure waveform will differ only in amplitude as a function of engine speed. By normalizing these waveforms, a motoring prototype waveform $p_{\text {zero }}(\theta)$ and a scaling factor $c_{1}$ that is a function of speed $N$ can be found from experimental motoring data. The component of cylinder pressure due to combustion is very difficult to determine analytically. By capturing cylinder pressure waveforms on a test engine in the laboratory while the engine is firing at different loads or fueling levels (FLVR), and subtracting the appropriately phased motoring waveform for each cylinder, a series of incremental pressure waveforms due to the combustion of a known amount of fuel is collected and analyzed. This analysis leads to a similar firing prototype waveform $\Delta p(\theta)$ and a scaling factor $c_{2}$ that is a function of speed $N$ and fueling level FLVR. These prototype waveforms and scaling factors are combined to compute individual cylinder pressure waveforms at any speed and any fueling level as

$$
\begin{aligned}
p(\theta, N, F L V R)= & p_{\text {zero }}(\theta) \bullet c_{1}(N) \\
& +\Delta p(\theta) \bullet c_{2}(N, F L V R)+p_{o}(N) .
\end{aligned}
$$

A block diagram showing this computation is given in Fig. 3 . Fig. 4 shows very good matching of measured and simulated pressure waveforms using this model.
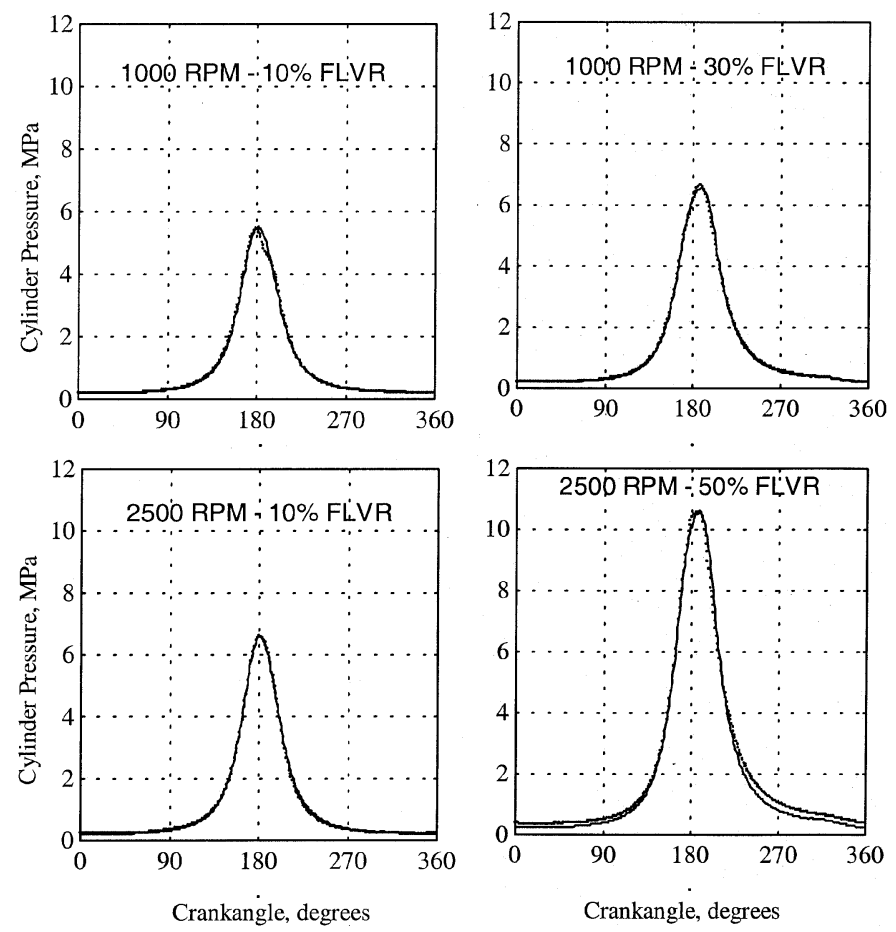

Fig. 4. Simulated (-) and measured ( ...) pressures (MPa) versus crankangle.

\section{ENGINE TORQue ObSERVER DESIGN}

To implement the "disturbance input decoupling" control, a measurement or estimate of the disturbance torque ripple is required. It is impractical due to expense and other issues to install a physical sensor for crankshaft torque, so an observer is designed to compute a nonlagging estimate of the engine torque ripple (or ac torque). The control strategy is to command the SA to produce the inverse of this ripple torque which, when added to the crankshaft torque, will cause the ripple to be cancelled or decoupled from the net output. It is also important not to have the SA producing any average (or "dc") torque, so the observer 


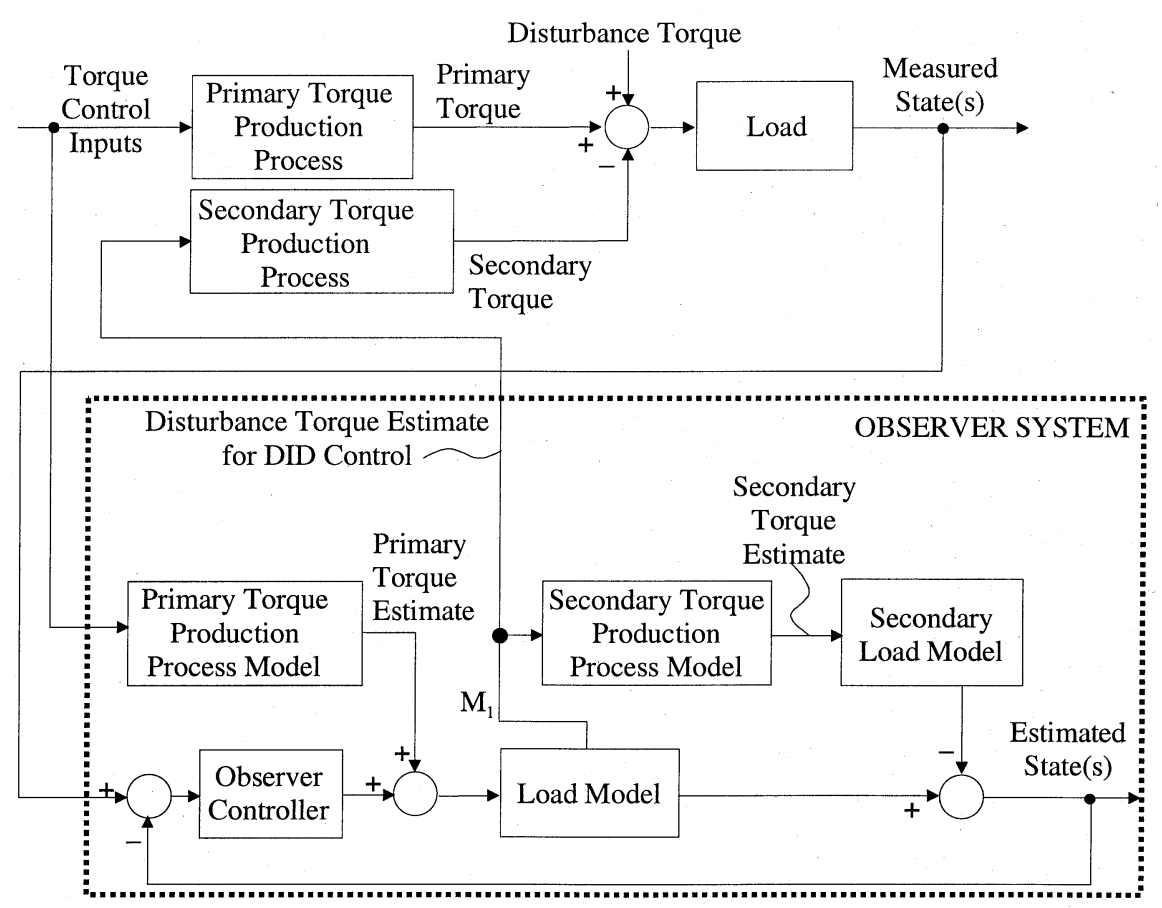

Fig. 5. Extended observer topology for active vibration control.

is designed to capture an estimate of only the ac content of the crankshaft torque.

The engine model described above must be extended to include the contribution of the starter alternator torque. Using this extended model as an observer, it is then possible to determine the appropriate ac torque to use as the "disturbance input decoupling" control signal $\hat{M}_{\mathrm{AC}}$. The observer topology is shown in Fig. 5 in general terms, and in detail in Fig. 6. The primary torque production process referred to in Fig. 5 is the internal combustion engine, while the secondary torque production process is the SA. It is vitally important with this technique to accurately represent the complete physical system in the observer and to include the effects of both physical processes to achieve a correct estimate. As seen in both Figs. 5 and 6 , the SA torque command $\left(\hat{M}_{\mathrm{AC}}\right)$ provided to the physical system must also be provided to the representation of the SA in the observer. The determination of this signal is the primary result of this work.

A one-to-one correspondence exists between the general blocks labeled in Fig. 5 and the sections of the detailed diagram shown in Fig. 6. In the observer, the quantities with a caret () represent estimates. These estimates are derived from the model previously developed. Note that, in the laboratory, a water brake was used to load the engine rather than a vehicle. Therefore, the load model in the observer of Fig. 6 includes an estimate of the viscous load of the water brake $\left(\hat{b}_{\text {WATER BRAKE }}\right)$. For the secondary load model, the main purpose is to capture the effect of the SA torque being applied in the physical system. However, this path also has a key role to play in defining the start of the frequency band over which the SA is active. In other words, the parameter $\hat{b}_{\mathrm{AC}}$ controls the start of the passband for the definition of the "ac" torque that the SA is commanded to produce to cancel the crankshaft ripple. The effect of this can be seen in Fig. 7, which is described in more detail below. For the observer controller, the gains $k_{i o}, k_{p o}$, and $k_{d o}$ are determined as described below.

Because the feedforward portion of the observer is open loop, motion state feedback from the physical system is used in the observer to make it closed loop. This corrects for any inaccuracies in the feedforward estimate [9], [10] according to the bandwidth of the observer controller.

Transfer function analysis is used here to tune the closed-loop observer, as has been done in previous work [11]. A simplified version of Fig. 6, using a linear approximation of the system and written in the continuous time domain, yields estimation accuracy transfer functions for speed and torque estimates. These are as follows:

$$
\begin{aligned}
H_{\mathrm{est} \_w}(s)= & \frac{\hat{\omega}(s)}{\omega(s)} \\
= & \frac{k_{d o} s^{2}+k_{p o} s+k_{i o}}{\left(\hat{J}+k_{d o}\right) s^{2}+\left(\hat{b}+k_{p o}\right) s+k_{i o}} \\
H_{\mathrm{est} \_M}(s)= & \frac{\hat{M}(s)}{M(s)}=\frac{\hat{J} s+\hat{b}}{J s+b} \\
& \cdot \frac{k_{d o} s^{2}+k_{p o} s+k_{i o}}{\left(\hat{J}+k_{d o}\right) s^{2}+\left(\hat{b}+k_{p o}\right) s+k_{i o}} .
\end{aligned}
$$

The fundamental frequency of the torque ripple is equal to engine revolutions per minute divided by 30 . In this work, the observer controller was designed for engine speeds from a very low idle of 500-2500 r/min, or 17-83 Hz. However, the torque has significant higher order harmonic content to which the linear observer controller will not be able to respond. This is why the accuracy of the feedforward element of the observer, based on 


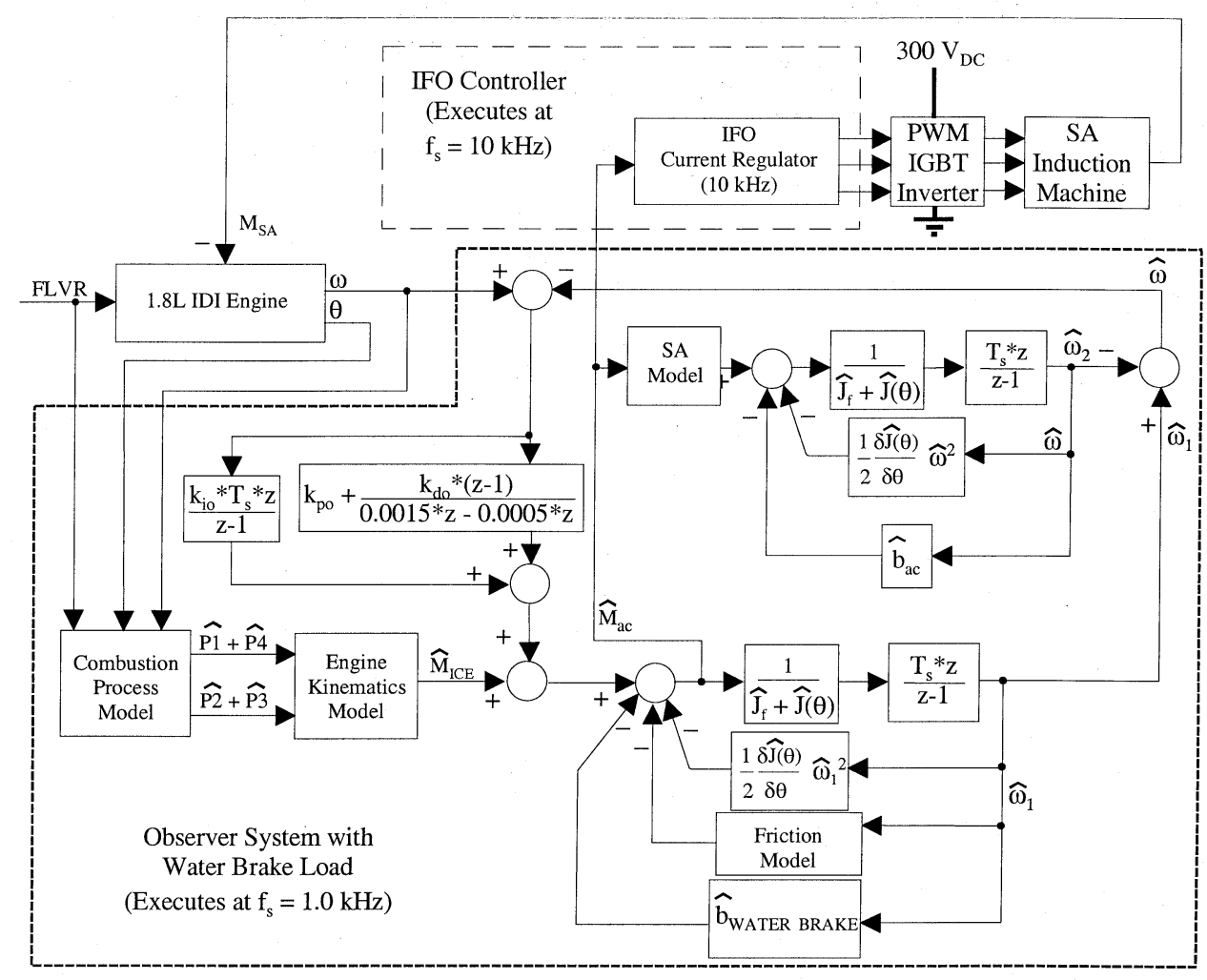

Fig. 6. Extended crankshaft torque observer and AFW controller implementation block diagram.
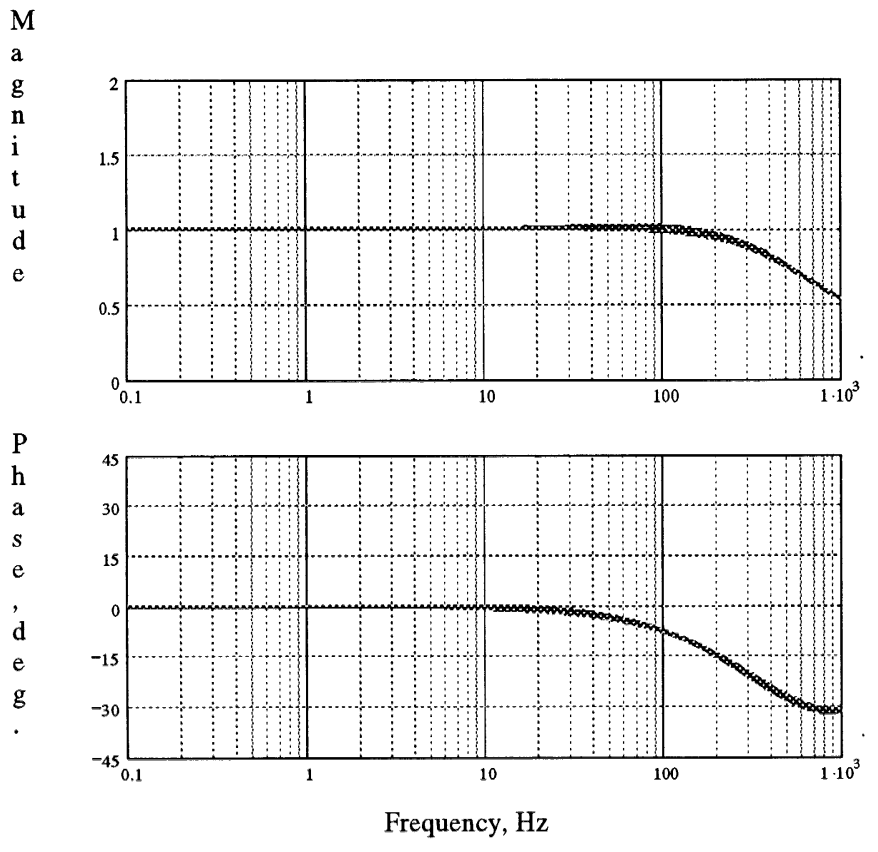

Fig. 7. Speed estimation accuracy frequency response function.

the combustion pressure estimation described above, is so important. From a practical point of view, the torque-ripple cancellation is most necessary at low engine speeds, wherein the SA rotor inertia does not provide much passive flywheel action and where the resultant vibration is most perceptible and objectionable to the vehicle occupants and the downstream driveline components. Therefore, for purposes of designing the observer controller, the selected bandwidth is $10-100 \mathrm{~Hz}$.

Equations (7) and (8) are used to design the controller gains $k_{i o}, k_{p o}$, and $k_{d o}$. Considering only the common portions of (7) and (8) which are affected by the gains, it is seen that a positive value of $k_{d o}$ has the effect of introducing a zero and moving the open-loop pole from to $\hat{b} / \hat{J}$ to $\hat{b} /\left(\hat{J}+k_{d o}\right)$. Reducing this pole is undesirable, indicating that $k_{d o}$ should be small or zero. Moving on to the proportional term, it is seen that the transfer function pole will move to

$$
\frac{\hat{b}+k_{p o}}{\hat{J}+k_{d o}} .
$$

By setting $k_{p o}$ one can set the bandwidth of the observer to a larger value. For a desired bandwidth of $f_{c}, k_{p o}$ can be determined as

$$
k_{p o}=2 \pi f_{c}\left(\hat{J}+k_{d o}\right)-\hat{b} .
$$

Finally, the integral term can be determined to maintain the resulting poles on the real axis for critical damping of the estimated torque and speed, resulting in

$$
k_{i o}<\frac{\left(\hat{b} k_{p o}\right)^{2}}{4 \hat{J}} .
$$

The two estimation accuracy frequency-response functions are plotted in Figs. 7 and 8 with variation for the damping parameter $\hat{b}$ and $f_{c}=100 \mathrm{~Hz}$ and $k_{d o}=0$. Note that the inertia value is assumed to vary little as it typically can be known fairly 

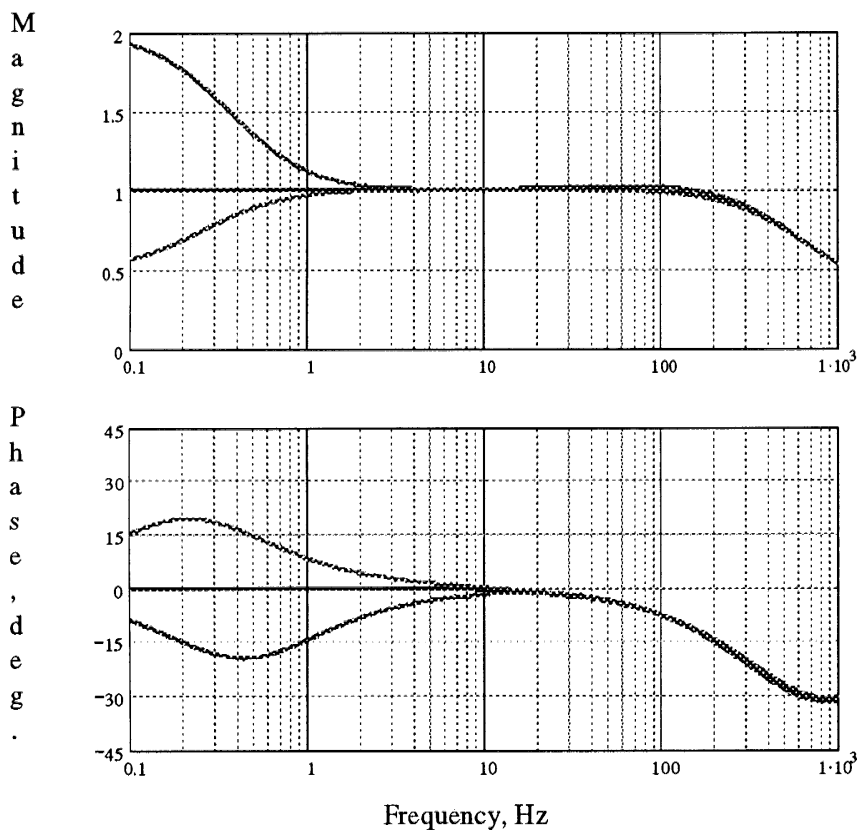

Fig. 8. Torque estimation accuracy frequency response function.

accurately a priori. Given these conditions, the speed accuracy is excellent up to the cutoff frequency, while the torque estimate suffers at low frequency. This will be seen to be inconsequential below, since the control transfer function is attenuated at low frequencies by design.

Once the observer controller has been designed, the transfer function of interest for the torque control is that between the indicated torque $M_{\mathrm{ICE}}$ and the observer output $\hat{M}_{\mathrm{AC}}$ because this transfer function will indicate the nature of the torque signal "extracted" by the observer to be used as a command for the SA. This transfer function is given in (12), as shown at the bottom of the page, and the corresponding Bode plot is shown in Fig. 9 (with variation of $\hat{b}_{\mathrm{AC}}$ shown). Fig. 9 clearly shows that the output $\hat{M}_{\mathrm{AC}}$ is equal to $M_{\mathrm{ICE}}$ in the desired passband, approximately $1-100 \mathrm{~Hz}$, and attenuated elsewhere, particularly at dc. This produces the desired signal for decoupling the ac disturbance torque using active flywheel control since this torque, if accurately produced by the SA machine, will be subtracted from the crankshaft torque resulting in the desired cancellation.

\section{ENGINE TeSt STAND AND RESUlts}

The control system described above has been implemented on a test stand consisting of a Ford 1.8-L turbocharged inter-cooled four-cylinder indirect injection diesel engine with an indirect field-oriented induction motor starter alternator directly coupled to the crankshaft where the flywheel would normally reside. A water brake is provided as a load. The test apparatus is shown schematically in Fig. 10. The field-oriented induction motor control block diagram is shown in Fig. 11 [16], [17].
A significant amount of testing was carried out over the speed range of idle $(850 \mathrm{r} / \mathrm{min})$ to $2000 \mathrm{r} / \mathrm{min}$, under loaded and unloaded conditions. Typical results for the observer are given in Figs. 12 and 13, and the active flywheel performance in Figs. 14 and 15. That is, Figs. 12 and 13 represent the case where the observer output is not controlling the SA, while Figs. 14 and 15 represent the case where the observer output is used as a control signal for the SA.

In Figs. 12-15, the cylinder pressures, indicated torque, and net torque signals are plotted versus crankangle (in degrees) because they were acquired with a data acquisition system triggered by one degree crankangle increments. The speed signals are plotted versus time because they were acquired by the control microprocessor. However, the speed signals are shown for a time increment representing approximately the same duration of data as the crankangle-plotted signals.

Figs. 12 and 13 show a sample of the very good tracking performance of the observed cylinder pressures, indicated and net torque, and engine speed signals. For the $850-$ r/min case represented in Fig. 12, the observed engine speed is seen to track virtually perfectly against the measured signal. Note that there is error on the measured $850-$ r/min speed signal every other pulse. This is due to noise on the position feedback which occurs every other crank revolution, thought to be due to variations in the air gap between the sensor head and its tone wheel target due to nonparallelism of the tonewheel and the rear face of the engine block. This noise becomes more evident in Fig. 13 at 1500 r/min. Note that these plots represent "passive flywheel" conditions as far as the SA is concerned, and the peak-to-peak variation in engine speed is about $160 \mathrm{r} / \mathrm{min}$ at $850 \mathrm{r} / \mathrm{min}$ (Fig. 12), while it is about $80 \mathrm{r} / \mathrm{min}$ at $1500 \mathrm{r} / \mathrm{min}$ (Fig. 13).

Figs. 14 and 15 show a sample of the results achieved for the active flywheel control using the starter alternator and the developed observer. Here the "net torque" signal is the same as the $\hat{M}_{\mathrm{AC}}$ signal. Fig. 14 shows that the speed ripple is reduced to $30 \mathrm{r} / \mathrm{min}$ peak-to-peak for the $850 \mathrm{r} / \mathrm{min}$ case, and to about $40 \mathrm{r} / \mathrm{min}$ for the $1500-\mathrm{r} / \mathrm{min}$ case. These substantial reductions in speed ripple from the passive cases represented by Figs. 12 and 13 are indicative of the effectiveness of the SA active torque control.

Because of natural attenuation of the output torque ripple by the flywheel action of the SA rotor and clutch inertias, it was found for this engine and test apparatus that there was no appreciable improvement in ripple reduction above $2000 \mathrm{r} / \mathrm{min}$.

\section{CONCLUSIONS AND DISCUSSION}

This paper has presented a simple method to actively control a starter alternator to decouple unwanted ac disturbance torque from internal combustion engines. The method is based on a flexible and accurate dynamic model of an internal combustion engine that is valid over all speeds and loading conditions. The model is extended to develop an observer capable of providing

$$
\frac{\hat{M}_{\mathrm{AC}}(s)}{M_{\mathrm{ICE}}(s)}=\frac{k_{d o} s^{2}+k_{p o} s+k_{i o}}{\frac{J s+b}{\widehat{J} s+\hat{b}}(\hat{J} s+\hat{b}+1)+\frac{J s+b}{\hat{J} s\left(\hat{J} s+\hat{b}_{\mathrm{ac}}\right)} \hat{b}_{\mathrm{ac}}\left(k_{d o} s^{2}+k_{p o} s+k_{i o}\right)+k_{d o} s^{2}+k_{p o} s+k_{i o}}
$$



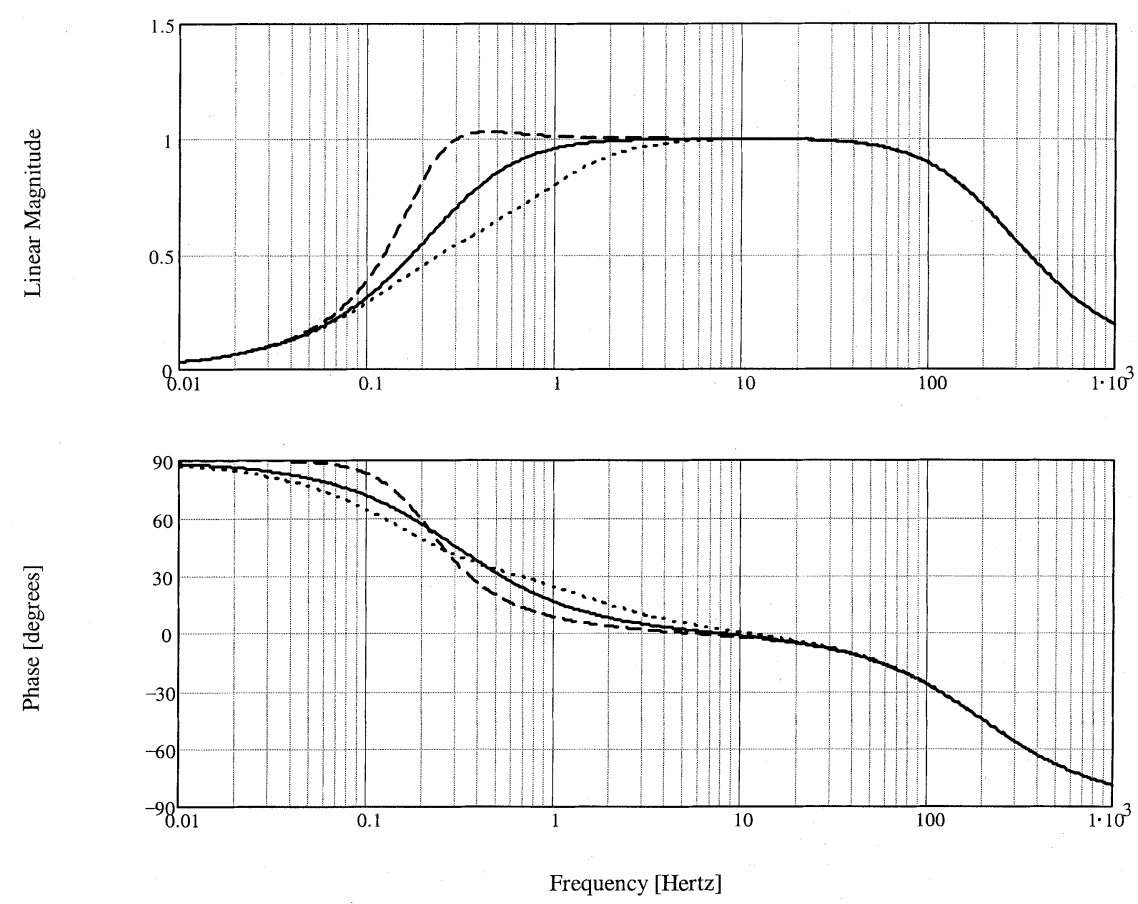

Fig. 9. Bode plot of $\hat{M}_{\mathrm{AC}}(s) / M_{\mathrm{ICE}}(s)$ for $\hat{b}_{\mathrm{ac}}=0.2(-), 0.4(--)$, and $0.1(\cdots) \mathrm{N} \cdot \mathrm{m} c d o t \mathrm{rad} / \mathrm{s}$.

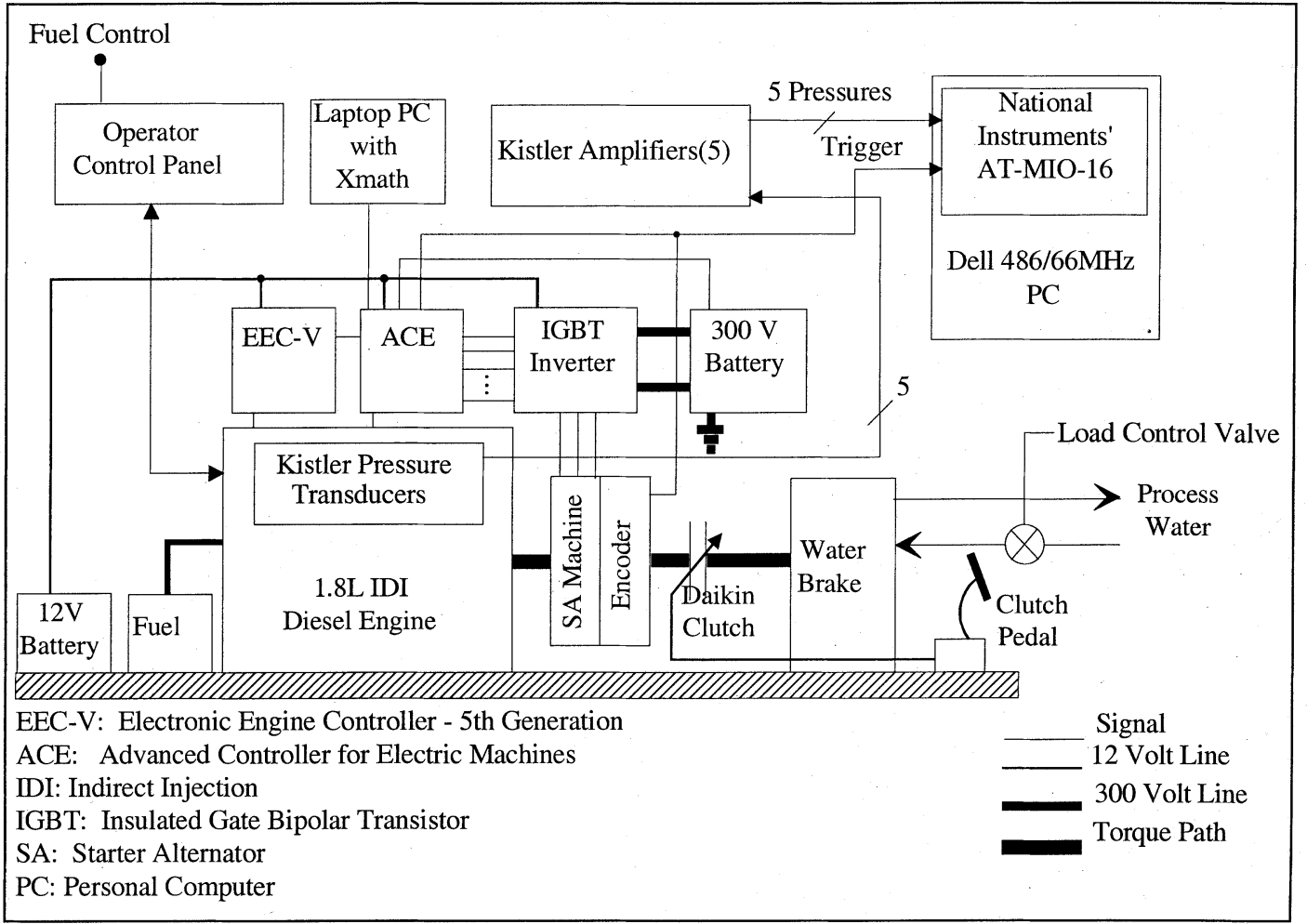

Fig. 10. Schematic of the engine test stand with SA and instrumentation.

a very-high-fidelity wide-bandwidth estimate of the crankshaft ripple torque content that can be used as a disturbance input decoupling control signal for a crankshaft-mounted integrated SA. The observer contains a feedback controller operating on crankshaft speed feedback derived from the position sensor used for the starter alternator control, such that no additional sensors are required to implement this torque control system. Test results were provided, showing very good performance both for the observer and the active flywheel control system.

It must be noted that there are several practical limitations not explicitly resolved by this paper. For example, as implemented, this active flywheel system draws a significant amount 


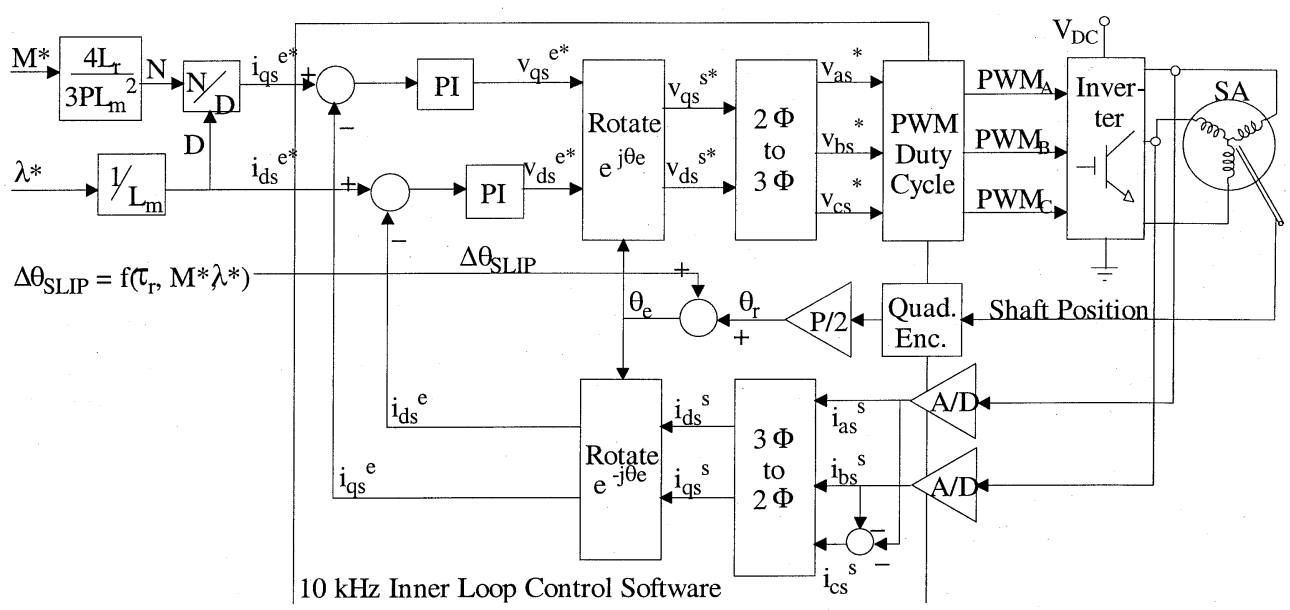

Fig. 11. Indirect field-oriented induction machine control block diagram.
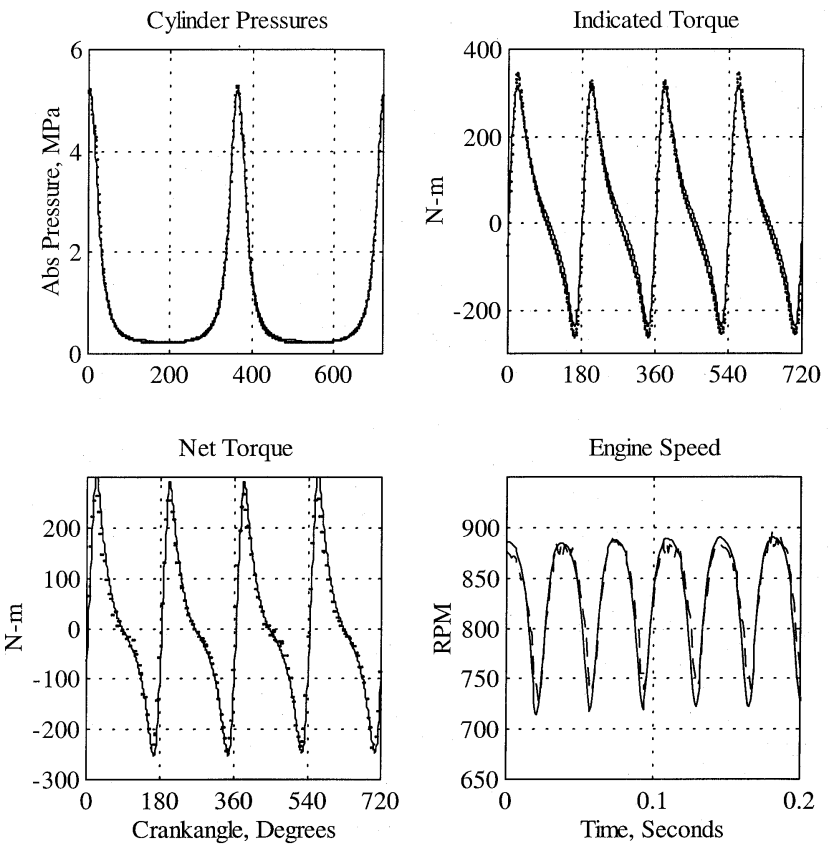

Fig. 12. Observer test results, $850 \mathrm{r} / \mathrm{min}$, no load: measured $(\ldots)$; observer (一); measured speed (- - ).

of power from the dc supply. This is primarily because the induction motor used in the experimental apparatus was designed as a relatively low power generator ( $\sim 3 \mathrm{~kW}$ continuous) and not as a high-power torque source $(\sim 15 \mathrm{~kW})$ as it was employed for this project. Therefore, the machine was significantly overdriven, operating at fairly high losses, even though the average output torque (hence, power) is zero. Secondly, only relatively low-speed operating points were discussed. This is because the active flywheel only needs to be active at low engine speeds because the natural filtering due to the rotor inertia, acting as a passive flywheel, is sufficient at high speeds. However, it is practical to operate at all times that the engine speed is below a certain level; in other words, it handles low-frequency speed changes well because of the attenuation of the control signal at low frequencies, as shown in Fig. 9. In fact, this "nonresponsiveness" of the active flywheel to low-frequency engine speed variations is a major advantage of the present system over traditional
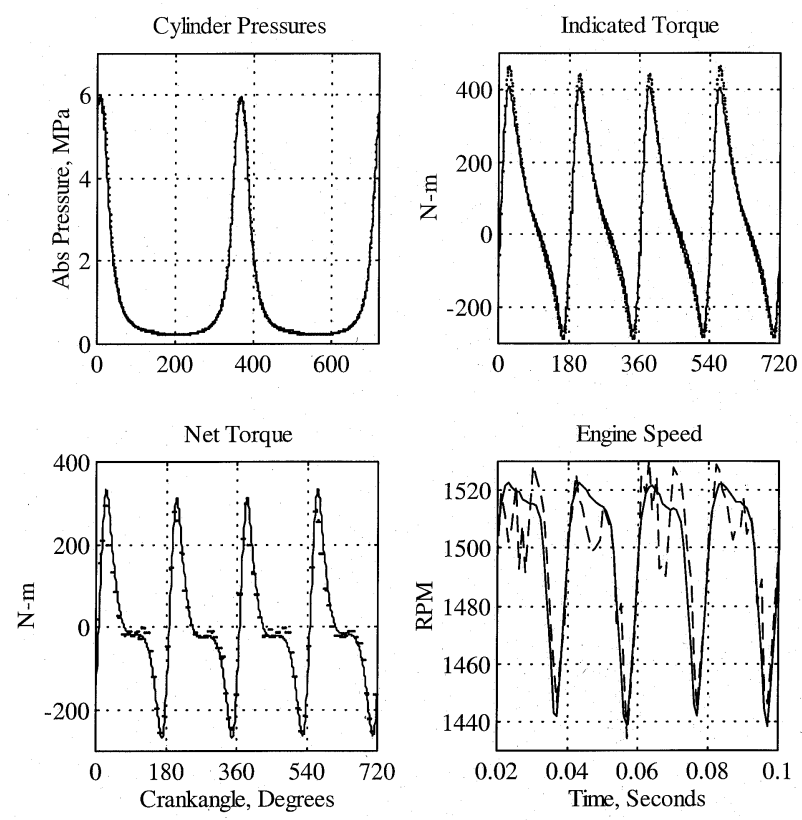

Fig. 13. Observer test results, $1500 \mathrm{r} / \mathrm{min}, 20 \%$ FLVR: measured $(\cdots)$; observer (-); measured speed (- - -).

active damping because it is difficult to distinguish between unwanted ripple and desired engine speed variations. Such desired speed variations arise from the dynamic driving conditions of the vehicle, and are generally well below $10 \mathrm{~Hz}$ when the engine is loaded.

A premise of this paper is that the practical issue of cost of the electric drive has been justified by the benefits of the hybridization of the powertrain. This, of course, is still a hotly debated question, even with the introduction of low-volume production of hybrid electric vehicles such as the Toyota Prius and Estima, the Honda Insight and Civic, and the forthcoming Ford Escape. Given the availability of the electric drive tightly coupled to the crankshaft, the functions described in this paper are indeed feasible from the point of view of computation and sensing. In other words, no additional sensors or significant computational resources are required beyond those necessary for field-oriented control of the machine. 

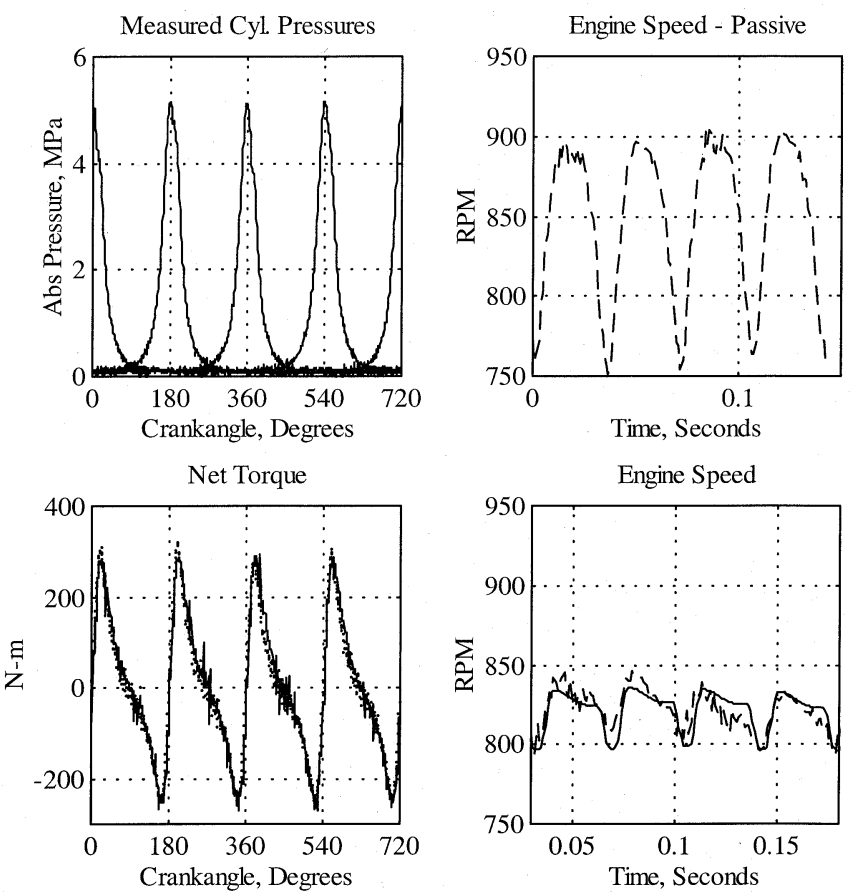

Fig. 14. Observer and AFW test results, $850 \mathrm{r} / \mathrm{min}$, no load: measured pressures (-); measured ( $\cdots$ ) and observed (-)torque; measured (- - ) and observed (一) speeds.
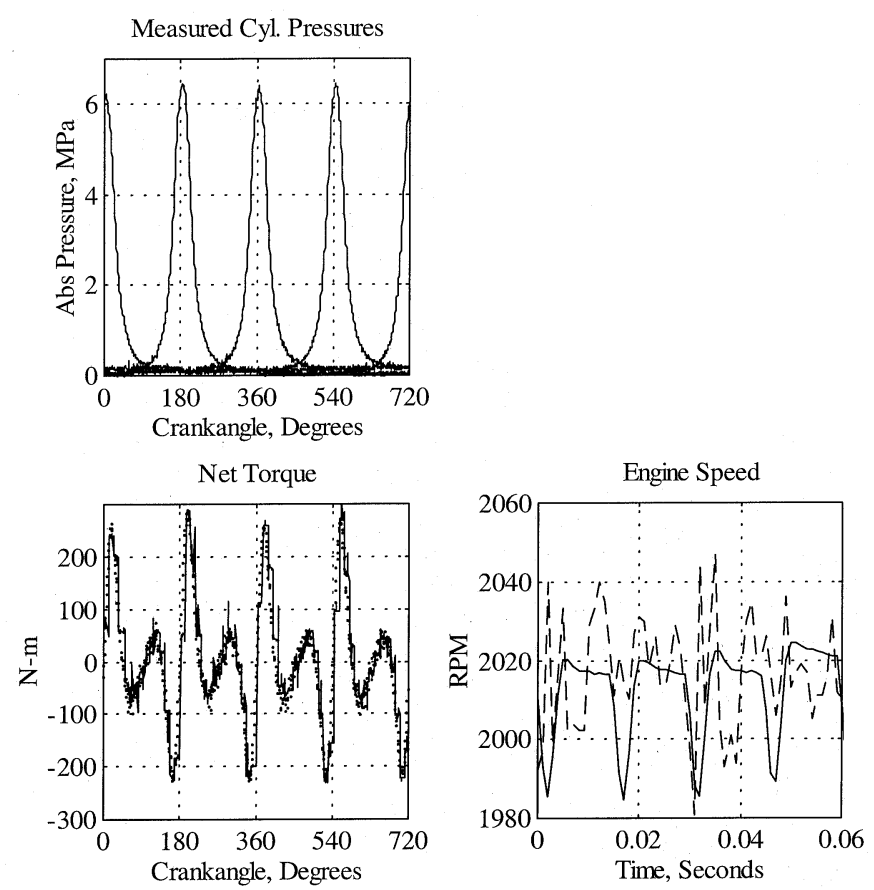

Fig. 15. Observer and AFW test results, $1500 \mathrm{r} / \mathrm{min}, 20 \%$ FLVR: measured pressures (-) measured ( ...) and observed (-) torque; measured (- - -) and observed (一) speeds.

Finally, with sufficient resolution of the position sensor and high sample rates of the observer, the techniques described herein are suitable for observing instantaneous engine speed and crankshaft torque over the entire operating range (speed and load) of the engine. Such an observer has obvious attraction for applications in engine control [11]-[14]. Selection of observer sample rates and position sensor resolution are simple aspects of classical control system design. However, it should be noted that the use of active torque cancellation is not required, and is undesirable, at high engine speeds because the natural flywheel action of the SA machine is sufficient.

\section{REFERENCES}

[1] J. G. Kassakian, H.-C. Wolf, J. M. Miller, and C. J. Hurton, "The future of automotive electrical systems," in Proc. IEEE Conf. Automotive Electronics, Dearborn, MI, Oct. 1996, pp. 3-12.

[2] H. Tashiro et al., "Vibration damping control apparatus for vehicle," U.S. Patent 5 537 967, July 23, 1996.

[3] L. K. Kouadio, P. Bidan, M. Valentin, and J. P. Berry, "S.I. engine idle control improvement by using automobile reversible 'alternator'," in Proc. IFAC 13th Triennial World Conf., San Francisco, CA, 1996, pp. 93-98.

[4] J. B. Heywood, Internal Combustion Engine Fundamentals. New York: McGraw-Hill, 1988.

[5] D. E. Winterbone, C. Thiraurooran, and P. E. Wellstead, "A wholly dynamic model of a turbocharged diesel engine for transfer function evaluation," SAE, Paper 770124, 1977.

[6] D. J. Dobner, "A mathematical engine model for development of dynamic engine control," SAE, Paper 800054, 1984.

[7] J. A. Cook and B. K. Powell, "Modeling of an internal combustion engine for control analysis," IEEE Contr. Syst. Mag., vol. 8, pp. 20-26, Aug. 1988.

[8] J. P. Jensen, A. F. Kristensen, S. C. Sorensen, N. Houbak, and E. Hendricks, "Mean value modeling of a small turbocharged diesel engine," SAE, Paper 910070, 1991.

[9] D. G. Luenberger, "An introduction to observers," IEEE Trans. Automat. Contr., vol. AC-16, pp. 596-602, Dec. 1971.

[10] B. Gopinath, "On the control of linear multiple input-output systems," The Bell Syst. Tech. J., vol. 50, no. 3, pp. 1063-1081, Mar. 1971.

[11] G. Rizzoni, "Estimate of indicated torque from crankshaft speed fluctuations: A model for the dynamics of the IC engine," IEEE Trans. Veh. Technol., vol. 38, pp. 168-179, Aug. 1989.

[12] G. Rizzoni, Y.-Y. Wang, and S. Drakunov, "Estimation of engine torque using nonlinear observers in the crank angle domain," in Proc. ASME DSC-56, Advanced Automotive Technologies, 1995, pp. 189-193.

[13] M. Kao and J. J. Moskwa, "Nonlinear diesel engine control and cylinder pressure observation,” ASME J. Dyn. Syst., Meas. Control, vol. 117, pp. 183-192, June 1995.

[14] _ - "Engine load and equivalence ratio estimation for control and diagnostics via nonlinear sliding observers," Int. J. Veh. Des., vol. 15, no. 3/4/5, pp. 358-368, 1994

[15] R. D. Lorenz, "New drive control algorithms (State control, observers, self-sensing, fuzzy logic, and neural nets)," in Proc. PCIM Conf., Las Vegas, NV, Sept. 3-6, 1996, pp. 275-289.

[16] R. D. Lorenz, T. A. Lipo, and D. W. Novotny, "Motion control with induction motors," Proc. IEEE (Special Issue on Power Electronics and Motion Control), vol. 82, pp. 1215-1240, Aug. 1994.

[17] D. W. Novotny and T. A. Lipo, Dynamics and Control of Induction Motor Drives. Oxford, U.K.: Clarendon, 1995.

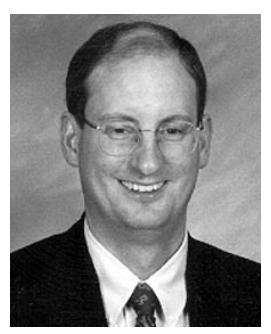

Roy I. Davis (M'00) received the B.S.E.E. degree from Michigan Technological University, Houghton, in 1982, the M.S.E.-E.C.E. degree from the University of Michigan, Ann Arbor, in 1989, and the Ph.D.M.E. from the University of Wisconsin, Madison, in 1999.

Since 1985, he has been associated with Ford Motor Company, initially hired into the Ford Research Laboratories, followed by a transfer in 1999 to Ecostar Electric Drives, LLC, which changed ownership to Ballard Power Systems Corporation in 2001. During this time, he has performed research and development work on automotive applications of electric drives and power electronics, and their control, including electric propulsion for EVs and HEVs, electric power steering, electric active suspension, and fuel-cell powertrain-related systems. Presently, he is the Manager of Advanced Systems Design for Ballard Power Systems, Dearborn, MI, engaged in system design and simulation for all aspects of Ballard's electric powertrain and power conversion products. 


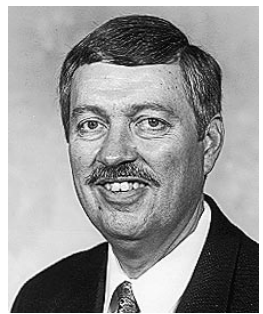

Robert D. Lorenz (S'83-M'84-SM'91-F'98) received the B.S., M.S., and Ph.D. degrees from the University of Wisconsin, Madison, and the M.B.A. degree from the University of Rochester, Rochester, NY.

Since 1984 , he has been a member of the faculty of the University of Wisconsin, Madison, where he is the Mead Witter Foundation Consolidated Papers Professor of Controls Engineering in both the Department of Mechanical Engineering and the Department of Electrical and Computer Engineering. He is Co-Director of the Wisconsin Electric Machines and Power Electronics Consortium, which celebrated its 20th anniversary in 2001. It is the largest industrial research consortium on motor drives in the world. He is also the thrust leader for control and sensor integration in the Center for Power Electronic Systems, an NSF Engineering Research Center (ERC) which is a joint ERC with Virgina Polytechnic Institute and State University, Rensselaer Polytechnic Institute, University of Puerto Rico-Mayaguez, and North Carolina A\&T. From 1972 to 1982, he was a member of the research staff at the Gleason Works, Rochester, NY, working principally on high-performance drives and synchronized motion control. He was a Visiting Research Professor in the Electrical Drives Group, Catholic University of Leuven, Leuven, Belgium, in the summer of 1989 and in the Power Electronics and Electrical Drives Institute, Technical University of Aachen, Aachen, Germany, in the summers of 1987, 1991, 1995, 1997, and 1999, where he also was the SEW Eurodrive Guest Professor from September 1, 2000 until July 7, 2001. In 1969-1970, he conducted Master thesis research in adaptive control of machine tools at the Technical University of Aachen. His current research interests include sensorless electromagnetic motor/actuator technologies, real-time signal processing and estimation techniques, precision multiaxis motion control, and ac/dc drive and high-precision machine control technologies. He has authored more than 160 published technical papers and is the holder of 16 patents, with two more pending.

Dr. Lorenz was the IEEE Industry Applications Society (IAS) President for 2001, a Distinguished Lecturer of the IAS for 2000/2001, immediate past Chair of the IAS Awards Department, and past Chairman of the IAS Industrial Drives Committee, and is a member of the IAS Industrial Drives, Electric Machines, Industrial Power Converter, and Industrial Automation and Control Committees. $\mathrm{He}$ is also the current Chair of the Periodicals Committee for the IEEE Technical Activities Board. He is a member of the IEEE Sensor Council AdCom. He is a Registered Professional Engineer in the States of New York and Wisconsin. He is also a member of the American Society of Mechanical Engineers, Instrument Society of America, and Society of Photo-Optical Instrumentation Engineers. He has won 15 prize paper awards. 